\title{
Factors resulting in non-utilization of Antenatal Care Services from Public Sector Hospitals in the rural area of Bahawalpur \\ Asia Aziz, ${ }^{1}$ Arooj Fatima, ${ }^{2}$ Mashal Fatima, ${ }^{3}$ Irum Hayat, ${ }^{4}$ Wajahat Hussain, ${ }^{1}$ Javaria Sadaf ${ }^{5}$
}

\begin{abstract}
Background: Knowledge regarding the factors impeding the using antenatal care would help in effective maternal and child health care delivery.

Objective: To enlist the barriers resulting in the non-utilization of antenatal care in public sector hospitals in Bahawalpur.

Methodology: This was cross-sectional study conducted in the catchment area of public sector healthcare facilities of Bahawalpur, from 20th February to 20th September 2019. The study population comprised of 152 females of childbearing age selected by systematic multistage random sampling technique. A pre-designed and pre-structured questionnaire was the tool for data collection from the study population. Data were analyzed using SPSS version 20.

Results: Non-utilization of antenatal care services was found in $44 \%$ of women. Barriers resulting in non-utilization of antenatal care were found to be as follows; permission not granted by husband in $25.37 \%$, no awareness about the availability of health services in $17.91 \%$, the distance of the residence from a health facility in $14.93 \%$, no awareness about the existence of health facility in $13.43 \%$, unavailability of medicines in $11.94 \%$, unavailability of staff in $8.96 \%$ and unfriendly staff in $7.46 \%$ women.

Conclusion: This study concluded that the main barriers experienced by consumers of public sector antenatal care services were permission not granted, distance from the residence, and awareness regarding health facility.
\end{abstract}

Keywords: Antenatal care, Barriers, Public Sector, Hospital

Article Citation: Arsalan HM, Abbas N, Aslam S, Yasmeen N, Rehman R, Farooq N. Evaluation of circulating Biochemical and Anti-oxidative Biomarkers in Patients with Beta-thalassemia from Lahore Pakistan. JSZMC 2020;11(3):08-12. DOI: https://doi.org/10.47883/jszmc.v11i03.128

\section{Introduction}

Irrespective of progress in some countries, globally the number of maternal death per year is about 529,000 and according to WHO, it has not changed prominently. ${ }^{1}$ Million of females survive but suffer from health issues and disability that ultimately causes problems in pregnancy. Since a long time ago, it is understood that maternal deaths can prominently be decreased in lowincome families by elevating access to professional doctors, which is closely linked to emergency obstetric and family planning services. $^{2-5}$ Despite of clear significance of maternity care that includes low access and utilization of services are important factors of maternal death throughout the world. ${ }^{2}$

Antenatal care (ANC) may be defined as the care of the women given by expert health-care professionals during pregnancy. Primary objective of ANC is the achievement of a healthy mother and baby at the end of pregnancy. Infant mortality rate i.e infant survival, is an important outcome measure for maternal and child health $(\mathrm{MCH}) .{ }^{2}$ Its primary purpose should be to ensure that woman is fit to bear the strain of pregnancy and to detect any abnormalities. ${ }^{3}$ World Health Organization (WHO) visualizes a world where each pregnant woman and infant receives proper care throughout the pregnancy, childbirth, and post-natal period by devising the Focused ANC model (FANC). The goal of this model is to provide and manage the complications of pregnancy itself, preexisting conditions that worsen during pregnancy, and the effects of an unhealthy lifestyle. ${ }^{4}$ Professional working staff in WHO recommended having care of least eight visits through-out the pregnancy period. ${ }^{5}$ Improving the access to ANC services for maternal has been proved an effective method for reducing the mortality and morbidity rate throughout the world. ${ }^{6-9}$ The evidence-based package of interventions to save newborn lives include antenatal learning and care during and after pregnancy, aid when the infant has

\footnotetext{
1. Department of Community Medicine,Quaid-e-Azam Medical College, Bahawalpur, University of Health Sciences, Lahore, Pakistan.

2. 2ndyear MBBS student,Quaid-e-Azam Medical College, Bahawalpur, University College of Medicine, University of Lahore, Pakistan

3. 4thyear MBBS student,Quaid-e-Azam Medical College, Bahawalpur, Pakistan.

4. Department of Community Medicine, Quaid-e-Azam Medical College, Bahawalpur, University of Health Sciences, Lahore, Pakistan.

5. Gynae and Obstetrics.Shahidaislam Medical College Lodhran, Pakistan.
}

Correspondence: Dr. Asia Aziz, Assistant Professor, Department of Community Medicine,Quaid-e-Azam Medical College, Bahawalpur, Pakistan. 
sign of birth asphyxia, providing antibiotics for suspected neonatal sepsis, and identifying highrisk neonates. ${ }^{10-14}$ The continuum of care is provided through the lifecycle approach starting from pre-pregnancy (birth preparedness) till postnatal care and by opportunities to address the gaps at all levels-family and community care, outreach services, and health care facilities. ${ }^{8}$ The Mother-Baby Package describes each intervention needed to achieve the safe-mother hood in the short term. Antenatal care is also one of the most important pillars of safe motherhood. ${ }^{9}$ This needs an effort to investigate the important factor affecting the uptake of ANC and different antenatal health services. As a result of these efforts, different socio-demographic characters of the mother have an impact on underlying ability to seek care. Another important factor for getting antenatal care services in Africa is the cultural background of females. ${ }^{15-18}$ A study in the rural district Ghana determined that expectant mothers had many excuses for not attending clinics for antenatal visits, that include distance to the health facility, transport difficulty, permission not granted, cultural reason, social reasons, and others. ${ }^{10}$

Pakistan is included in low and middle-income countries of South East Asia. The burden of maternal and fetal morbidity and mortality is much high in our country despite the implementation of antenatal care programs. Depending upon the results of the current study, some practical recommendations may be made for managing and preventing these barriers to implement proper antenatal care programs in the terms of proper access and utilization for preventing maternal and fetal morbidity and mortality leading to their improved survival. This study was conducted to highlight the barriers resulting in the non-utilization of antenatal care in public sector hospitals in Bahawalpur.

\section{Methodology}

This is cross-sectional study was conducted from $20^{\text {th }}$ February to $20^{\text {th }}$ September 2019 in the catchment area of public sector health care facilities (Rural Health Centre Lalsohanra, Basic Health Unit Sanjar, and Jhangiwala). The study population comprised of $n=152$ pregnant ladies of age 18-45 years living in the catchment area of all the above-mentioned health care facilities.
Women from other areas as described above were excluded. To reach the required sample size, multistage simple random sampling was done. There are total of 4 RHCs and 13 BHUs in Bahawalpur Tehsil. We selected one RHC and two BHUs by a simple random sampling technique. These were RHC Lalsohanra, BHU Sanjar, and BHU Jhangiwali. There are 6639 households in the catchment area of RHC Lalsohanra, 5198 in BHU Sanjar, and 3786 in BHU Jhangiwali. As the required sample size was 152 so proportionately 64 , 51, and 37 households were selected from RHC Lalsohanra, BHU Sanjar, and Jhangiwali respectively. Data was collected by introducing a pre-designed, pre-tested questionnaire. The questionnaire was designed in such a way as to get more qualitative information keeping objective of the study in mind. Statistical analysis was performed by using the software SPSS 20. Mean and standard deviation was calculated for the quantitative variable. Frequency and percentages were calculated for the qualitative variable.

\section{Results}

Out of 152 selected women, 85 received antenatal services and 67 did not. So, the non-utilization of ANC services was found in 67 (44\%) women.

Table-I: Reasons for non-utilization of the public sector for Antenatal Care during last pregnancy by respondents $(n=67)$

\begin{tabular}{|l|c|c|}
\hline \multicolumn{1}{|c|}{ Reasons } & Frequency & Percentage \\
\hline $\begin{array}{l}\text { Not aware of the existence of } \\
\text { health facility }\end{array}$ & 9 & 13.43 \\
\hline $\begin{array}{l}\text { Not aware of the availability } \\
\text { of health services }\end{array}$ & 12 & 17.91 \\
\hline Staff not available & 6 & 8.96 \\
\hline Medicine not available & 8 & 11.94 \\
\hline Distance & 10 & 14.93 \\
\hline Unfriendly staff & 5 & 7.46 \\
\hline Permission not granted & $\mathbf{6 7}$ & 25.37 \\
\hline Total & $\mathbf{1 0 0}$ \\
\hline
\end{tabular}

Table-I shows the barriers resulting in the nonutilization of antenatal care, among mothers who did not avail antenatal care services during last pregnancy, were found to be as follows; permission 
not granted by husband in $25.37 \%$, no awareness about the availability of health services in $17.91 \%$, the distance of the residence from a health facility in $14.93 \%$, no awareness about the existence of health facility in $13.43 \%$, unavailability of medicines in $11.94 \%$, unavailability of staff in $8.96 \%$ and unfriendly staff in $7.46 \%$ women (Table-I).

The majority of women $(89.55 \%)$ who had not received antenatal services were illiterate and belong to low socioeconomic status $(70.15 \%)$. All the barriers resulting in the non-utilization of antenatal care have shown a significant association with education status and low socioeconomic status ( $p$ value $=0.05$ ).

\section{Discussion}

In this study, the ANC service utilization rate was $55.92 \%$, which is quite similar to other local studies done in Punjab (55.92\%), ${ }^{11}$ Sindh $(57.3 \%){ }^{12}$ Malakand (47\%), ${ }^{13}$ and KPK (57\%) Some international studies were done in different populations i.e. district Mohali India (77\%), ${ }^{15}$ Ethiopia (63.77\%), ${ }^{16}$ Northern Nigeria $(98.7 \%),{ }^{17}$ Gorkha Nepal $(76 \%),{ }^{18}$ central Nepal $(60.7 \%),{ }^{18}$ and Japan $(46.1 \%)^{19}$ have shown a quite higher percentage of ANC service utilization rate as compared to our study. However, this rate was observed to be different in Jhang (35\%) and Sindh $(14 \%) .^{20,12}$ This low level of utilization in Jhang may be due to its rural background, in Sindh due to lack of comprehensive knowledge about the importance of MCH services utilization and cost. ${ }^{20}$ Current study revealed that (44\%) did not go for antenatal checkups, the main barriers were as follows, 17 ladies $(25.37 \%)$ were not granted permission by husbands. These results are quite similar to studies done at KPK (23\%), ${ }^{14}$ Kaduna state and Kano State of Northern Nigeria $(21.2 \%){ }^{21}$ West Java Province, Indonesia ${ }^{22}$, and Bayelsa state, Nigeria. ${ }^{23}$ In the current study, awareness about the availability of health services in the area was seen by $17.91 \%$. Almost similar findings were observed in surveys done in Ethiopia Tigary Zone (28.2\%) and Hadiya Zone $(19 \%){ }^{16}$

Distance as a barrier was reported by 10/67 $(14.93 \%)$ in our study which is quite consistent with the rate at Jhang, ${ }^{20} \mathrm{KPK},{ }^{14}$ Northern Nigeria, ${ }^{17}$ Tigary region Ethiopia, Hadiya Zone Ethiopia, ${ }^{16}$ Indonesia, ${ }^{22}$ Xiengkhouang and Bayelsa state of
Nigeria studies. ${ }^{23}$ In the current study, no awareness about the existence of a health facility in the area was observed in $9(13.43 \%)$ respondents. In studies done at Kaduna, Bayelsa state, ${ }^{23}$ Malakand Pakistan ${ }^{13}$, and Punjab, India, ${ }^{15}$ same barriers were seen hindering the utilization of ANC services.

The availability of medicines works as an incentive for attending patients, 8/67 females (11.94\%) said that medicines were not available at the health facility in this study. Similar findings were observed at Kaduna State Northern Nigeria, Uganda. ${ }^{21}$ According to $6 / 67$ females $(8.96 \%)$, the staff was not available $(6 \%)$ women. The same barrier was perceived in a study done at Kaduna State Northern Nigeria and Bayelsa state. ${ }^{21,23}$ Permission from husband, impeded the use of ANC utilization, distance suggested an insufficiency of geographical access to ANC services and decreased awareness/knowledge about availability led to less utilization in our study, a similar complaint was made by the subjects at Kaduna State Northern Nigeria. ${ }^{24}$

A review of different studies from various countries depicts that ANC utilization rate is less because of many factors that are required to be inspected like socio-economic characters, knowledge about ANC services. ${ }^{25,26}$ Maternal and child health care is not only linked to health facilities provided by private or government sectors, but it is also related to mothers including their learning skills, culture, socioeconomic status, and professional development. ${ }^{16}$ For instance, a study in Xien Khouang Province, Lao $\mathrm{PDR},{ }^{27}$ represent the prominent indicators of ANC utilization were different levels of education, knowledge, attitude, availability of transport, cost of services. Unavailability and low utilization of modern health care services are major reasons for poor health in developing countries. ${ }^{28}$ There are few studies conducted to assess the ANC use among females with the overall aim to suggest recommendations for the improvement of plans and programs launched for ANC in a specific manner so it is necessary to know those females and their families not getting proper care.

Some limitations of this study include; study design was cross-sectional so that the link present may not be explained as a casual relationship of temporal nature, data in this study was collected from only a single district, so that the results cannot be collected from all over Pakistan. Thus the generalizability of the findings may be compromised. The women who had given birth in two years were included in the 
study as participants. Therefore, further studies are needed to consider factors such as parity and place of birth.

\section{Conclusion}

This study concluded that that the main barriers of antenatal services utilization in the public sector hospitals in the rural area of Tehsil Bahawalpur are that; the majority of people are illiterate, not aware of the availability of health services. According to a large percentage of people the health facility is at a far distance. The other barriers are people who have not enough money to travel and go to the Health Centre. Lack of adequate staff, no awareness regarding the checkups during and after pregnancy, bad behavior of staff are other barriers regarding antenatal care services utilization in the public sector hospitals in rural areas of Tehsil Bahawalpur. In Pakistan, the presence of a complicated structure of the health system is leading to the formulation of " mixed health system syndrome". There should be coordinated, combined, and continuous efforts in formulating and implementing health promotion campaigns, focusing on vulnerable sectors of the population.

Authors' contribution: AA: Conception and Design of work, acquisition of data, analysis and interpretation of data, drafting. AF, MF: Acquisition of data, drafting and revising of manuscript. IH: Design of work, Acquisition of data and drafting. WH \& JA: Conception, acquisition of data, critical revision of the manuscript.

All the authors gave final approval for publication and agreed to be accountable for all aspect of work.

\section{Conflict of Interest: None \\ Sources of Funding: Self}

\section{References}

1. Park K, Park S. Preventive medicine in obstetrics, paediatrics and Geriatrics. Text book of Preventive and Social Medicine.24th edition. Jabalpur India: Banarsidas Bhanot; 2017;(10):558-60.

2. Maxcy-Rosenau W. Health-care planning, organization, and evaluation. Public Health Preventive Med. 2007;(79):1295-8.
3. Ghazi A. Human reproductive health issues. Public Health Commun Med. 2016;(11):933-5.

4. Ramesh G, Reddy JAV, Vardhan MV. Review of focused antenatal care. J Evi Based Med Health Care. 2015;28(2):331-6.

5. Ali SA, Dero AA, Ali SA. Factors affecting the utilization of Antenatal care among pregnant women: A literature review. J Pregnant Neonatal Med. 2018;2(2):41-5.

6. Yasuoka J, Nanishi K, Kikuchi K, Suzuki S, Ly P, Thavrin $\mathrm{B}$, et al. Barriers for pregnant women living in rural, agricultural villages to accessing antenatal care in cambodia. a community based cross-sectional study combined with geographic information system. PLos ONE. 2018;13(3):e0194103.

7. Tinker R. Parker D, Grear LK. Advancing newborn health: The saving Newborn Lives initiative, Global Public Health. 2010;5:1,28-47.

8. Lawn J, Kerber K. Opportunities for Africans newborns: practical data policy and programmatic support for newborn care in Africa. Partnership Maternal Newborn Child Health. 2006;1:250.

9. World Health Organization .Mother-baby package: implementing safe motherhood in countries: practical guide. 1996.

10. Samankuuro J, Crockett J, Wang S. The use of antenatal care in two rural districts of upper West Region, Ghana. PLoS ONE. 2017;12(9):e0185537.

11. Majroh AM, Husnain S, Akram J, Siddiqui A, Zahid M. Coverage and Quality of Antenatal Care provided at primary health care facilities in the 'Punjab' province of ' Pakistan. PLos ONE. 2014;9(11):e113390.

12. Noh JW, Kim YM, Lee LJ, Akram N, Shahid F, Kwon YD, et al. Factors associated with the use of antenatal care in Sindh province, Pakistan: a population- based study. PLos ONE. 2019;14(4):e0213987.

13. Ali H, Ali A, Mehmood QK, Jalal A, Ali SR. Antenatel care: accessibility issue among pakhtun women in Malakand, Pakistan. Isra Med J. 2018;10(6):362-6.

14. Khan N, Khan S, Khan N, Khan S. Factors affecting utilization of maternal and child health services: District Swat KPK Pakistan. Int J Innov Res Develop. 2013;2(8):217-26.

15. Pahwa P, Sood A. Existing practices and barriers to access of MCH services- a case study of residential urban slums of District Mohali, Punjab, India. Global J Med Public Health. 2013;2(4):4-5.

16. Tekelab T, Chojenta C, Smith R, Loxoton D. Factors affecting utilization of antenatal care in Ethiopia: a systemetic review and metaanalysis. PloS ONE. 2019;14(4):e0214848.

17. Idris SH, Sambo MN, Ibrahim MS. Barriers to utilization of maternal health services in a semi-urban community in northern Nigeria: the clients' perspective. Niger Med J. 2013;54:27-32.

18. Awasthi MS, Awasthi KR, Thapa HS, Saud B, Pardhan S, Khatry RA. Utilization of antenatal care services in Dalit communities in Gorkha, Nepal: a cross-sectional study. J Pregnan. 2018;2018:1-8.

19. Yang YE, Yoshida Y, Haroon-or-Rashid MD, Sakamoto J. Factors affecting the utilization of antenatal care services among women in Kham District, Xiengkhouang Province, LAO PDR. Nagoya J Med Sci. 2010;72:23-33. 
20. Agha S, Carton TW. Determinants of institutional delivery in rural Jhang, Pakistan. Int Equity health J. 2011;10(31):1-12.

21. Yar'zever IS, Said IY. Knowledge and barriers in utilization of maternal health care services in Kano State, Northern Nigeria. European J Biol Med Sci Res. 2013;(1):1-14.

22. Titaley CR, Hunter C, Heywood P, Dibley MJ. Why don't some women attend antenatal and post natal care services: a qualitative study of community members' perspectives in Garut, Sukabumi and Ciamis districts of West Java Province, Indonesia. BMC Pregnancy Child Birth 2010;10:61.

23. Olayinka OA, Achi OT, Amos AO, Chiedu EM. Awareness and barriers to utilization of maternal health care services among reproductive women in Amassoma community, Bayelsa state. Int J Nurs Midwifery. 2013;6(1):10-5.

24. Butawa NN, Tukur B, Idris H, Adiri F, Kelly D. Knowledge and perceptions of maternal health in Kaduna State, Northern Nigeria. Afr J Reprod Health.
2010;14(3):71.

25. Simkhada B, Teijlingen E, Porter M, Simkhada P. Factors affecting the utilization of antenatal care in developing countries: systematic review of the literature. J AdvNurs. 2007;61:244-260.

26. Hoesein AA. Empowering women in autonomy and decentralization processes: an Indonesian experience. Available from: http://www.indonesiamissionny.org/issuebaru/Mission/empwr/paper abdulazis]

27. Ye Y, Yoshida Y, Rashid OR, Sakamoto J. Factors affecting the utilization of antenatal care services among women in Kham District, XiengKhouang Province, Lao PDR. Nagoya J Med Sci 2010;72: 23-33.

28. Amin R, Chowdhury SA, Kamal GM, Chowdhury J. Community health services and health care utilization in rural Bangladesh. Soc Sci Med 1989;29: 1343-49. 